\title{
Effective Teaching: Application of BOPPPS Model in ESL Class
}

\author{
Yan Li \\ English Department \\ Binhai School of Foreign Affairs of Tianjin Foreign Studies University \\ Tianjin, China
}

\begin{abstract}
While more and more people are learning English as their second language in China, most of them fail to speak or write in English. The effectiveness of English teaching is challenged. To address this issue, the author introduces BOPPPS model in ESL class. Firstly, the author analyzes the effectiveness of ESL class and the dimensions of effective ESL class. Then, BOPPPS model is introduced and a comparison between BOPPPS model and traditional class is made. At last a tentative step is made by introducing BOPPPS model to ESL class, which is followed by some suggestions in employing BOPPPS model.
\end{abstract}

\section{Keywords-BOPPPS Model; ESL class; student-centered}

\section{INTRODUCTION}

English has become a global language. More and more people all across the world are learning it as a second language (ESL). Take China as an example. There are 400milllion English learners, among whom, however, only 5\% can communicate with others in English without difficulty or causing misunderstanding. Chinese students start to learn English since there are in primary school or even kindergarten. Most of them still fail to neither speak nor write in English, let alone effective communicate in crosscultural communication. English they have learned, therefore, is dubbed as "dumb English". After years of English study, they are still not competent in English. In face of this, the effectiveness of English teaching is challenged. It is highly important that the causes of the ineffectiveness of English teaching be found and effectiveness of ESL class be improved.

\section{THE EFFECTIVENESS OF ESL CLASS}

\section{A. Definition of Effectiveness}

According to Wikipedia, "Effectiveness is the capability of producing a desired result. When something is deemed effective, it means it has an intended or expected outcome, or produces a deep, vivid impression." When it comes to "effectiveness", people tend to approach to it from the economic perspective. In other words, if teacher put less effort and less time in ESL class, but generate more outcome, or students learn more knowledge and language skills, it is deemed effective ${ }^{1}$.
Generally speaking, the connotations of effective teaching are as follows ${ }^{2}$ :

- Outcome: the outcome of the teaching activity meets the desired objectives;

- Efficacy: efficacy of teaching activity = outcome of teaching activity / input of teaching activity;

- Benefit: teaching objective meet the demand of the society and individuals that receive the education.

It is also believed that if the teaching is effective, students may concentrate on learning in the course of class. They are attracted by the opening of the class, and inspired by it. Information relating to the class is activated for further study. They are clear what objectives they are going to achieve. They are always aware of what they are doing now and how it relates to the objectives. They are interested in and focus on the study because they play a part in the study by participating in it. They work under a certain degree of pressure because later on they are checked and evaluated ${ }^{3 .}$

\section{B. Dimensions of Effectiveness in ESL Class}

In order to decide whether an ESL class is effective, we need to take the objectives of learning English as a second language into consideration. After a comprehensive study of the documents related to language study, it is obvious that effective ESL class should aim at improving following competences of learners:

1) Linguistic competence: The concept of linguistic competence was first put forward by Chomsky, an American linguist, in his works Aspects of the Theory of Syntax ${ }^{4}$. He holds that the objective of learning a language is to master its grammar. Linguistic competence also involves the knowledge system of a language, including rules of etc ${ }^{5}$.

The first and foremost objective for English learners is to master adequate vocabulary, which build the trunk of the tree of sentences and paragraphs, the grammar, which help construct sentences or paragraphs with vocabulary, and pronunciation, which materialize all the ideas and concepts one wants to express through language.

For ESL learners, these competences are generally mentioned in terms of following aspects: 
- ESL learners should be able to understand conversation, news, etc spoken in English;

- ESL learners should be able to comprehend English articles, documents, or novels, etc;

- ESL learners should be able to speak in English fluently;

- ESL learners should be able to write in English;

- ESL learners should be able to translate or interpret from English to Chinese or vice versa.

2) Communicative competence: $\mathrm{Hymes}^{6}$ inherits and improves Chomsky's theory on linguistic competence and coins "communicative competence" in his On communicative competence. He points out that communicative competence is the ability of applying the knowledge and skills of the language that one has learned. It involves whether a language is grammatically correct, whether it is acceptable psychologically, whether it is appropriate in certain social conditions, and whether it is often used in daily life ${ }^{7}$.

Based on communicative competence, Canale and Swain construct the model of communicative competence. They hold that communicative competence consist of the following aspects:

- Grammatical competency, which includes phonic, lexical and syntax knowledge;

- Context competency, namely, to combine form and meaning of a language into a passage / context through various ways;

- Social linguistic competence, which means to correctly understand or express ideas in a language in specific social context;

- Competence of employing certain strategies, namely to achieve effective communication through necessary strategies both verbal and non-verbal.

3) Cognitive ability: Apart from linguistic competency and communicative competency, cognitive ability can also be cultivated from effective teaching. It is believed that a higher cognitive ability contributes to higher possibility of success. Although not explicitly stipulated in any syllabus of ESL class, the students gain cognitive ability through receiving, assorting, processing, and storing of information. If they apply what they have learned to daily life, they may gain more cognitive ability.

Furthermore, the information they receive from an ESL class is from a different culture, which embodies a different way of thinking. Therefore, in addressing an issue, they are confronted with different approaches by different way of thinking. In the constant collision of ways of thinking, and by frequent exposed to new issues and working out solutions to these issues, their cognitive ability improves ${ }^{8}$.

\section{Obstacles of Effective ESL Class}

1) Drawbacks of the process of traditional ESL class: Normally, an ESL class is divided into three parts: introduction or warm-up of the class, lecture on the text, and, a short summery ${ }^{9}$. It is assumed that whenever a teacher introduces a new text or topic, he/she needs to prepare students for it by providing related information, which may help students get acquainted with what they are going to learn. This warm-up section often lasts 10 to 15 minutes. Sometimes, it lasts longer because the teacher needs to introduce new vocabulary of the new text or topic.

Then the teacher starts a long discourse on the text. He firstly introduces the meaning of important words, idioms, collocations, expressions, and then, by drawing on the knowledge of the grammar, explains the meaning of each sentence. Sometimes, this discourse also includes genre and rhetorical devices of the text, the author's attitude, etc. The long discourse is often joined by a few questions to remind students that they should concentrate on learning. This monotonous section dominates the class and often makes up $2 / 3$ of the class.

As last, almost at the end of the class, the teacher may summarize the key words, important grammar the content that they have learned in the class. Sometimes, students are encouraged to discuss and report or replay what they have learned. This section last even shorter-normally five to ten minutes. Then the class ends.

This way of teaching lacks variation. The teacher dominates the whole class, and correspondingly, time dedicated to practicing what they have learned is minimized, which is a great obstacle for students to improve their linguistic competency in ESL class. What's more, it is difficult for him/her to learn how well students proceed in their study. Though these three steps-review/warm-up, lecture, and summary - are necessary in ESL class, the allocation of time can still be optimized for the lecture by the teacher lasts too long.

2) One-way Teaching Method: In a traditional ESL class, teachers always take the lead. They are the absolute authority of the class and the students are supposed to be their loyal audience. The drawback of this one-way teaching method is acknowledged by most English teachers. In spite of this, most teachers are still reluctant to change it into "teacher as facilitator, and student-centered class", due to the requirements of the syllabus, the textbook, and the requirement of the curriculum. What's more, they are used to one-way teaching, and the students are accustomed to be audience and are ready to receive what the teachers give.

Apparently, this one-way teaching method is effective, because teachers, without any disruption in their discourse, impart a lot of knowledge. But, in fact, language study is not all about listening and learning. ESL learners need a lot of practice. For this end, They need actively involved into the study by asking or answering questions related to the content of the class, discussing, role-playing, etc. Otherwise, the content of the class, which is supposed to be interesting and 
meaningful, has become stuff. Passive study not only fails to help ELF learners improve their English but also make them easily lose interest in the class or get distracted by monotonous discourse.

Furthermore, it is believed that lecture generates the lest efficacy in learning-5\%, followed by reading- $10 \% \mathrm{~m}$ audio-visual-20\%, demonstration-30\%, discussion group $-50 \%$, practice by doing- $75 \%$, and teaching others, which is immediate use of learning-90\%(Edgar Dale, 1946). According to Edgar Dale low efficiency of learningefficiency below 30\% is deemed low--happens in personal study or passive study, while high efficiency-above $50 \%$ takes place in teamwork, active learning and participatory learning. "Fig. 1"

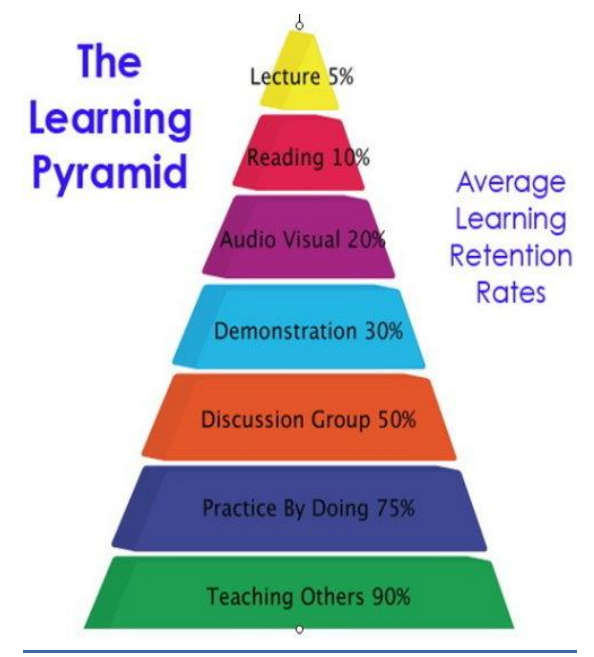

Fig. 1. The learning Pyramid

3) Less Participation of Student: In the teachercentered ESL class, students are seen as vessels. Teachers put knowledge into the vessels and assume that they can absorb all of them. They neglect that student, as intelligent individuals, who have unique interest and various demands. The way they take in information or learn new things differs from person to person for they need to draw on their unique life experience, emotional feelings, way of thinking and personal values. Take all of these into consideration, the role of students play in the class cannot be neglected. It is important that teacher-centered ESL class should give way to student-centered one.

What is more, in learning English as a second language, students need more chance to practice, either through answering questions or through actively involved in in-class activities. It is deemed that learning a language is like learning how to use a tool. Without practicing, one can never be the master of it. Less participation and practice may lead to passive study, and students are easily bored in their study. Furthermore, it is difficult for them to assimilate what they have learned, let alone the application of the language.

4) Lack of feedback from students and deferred evaluation: There is no time left to look back and check the performance of the students since teacher's lecturing takes up most of the time of an ESL class. Without and feedback from the students, the teacher has no idea about how well they have learned and whether they have accomplished the objectives of teaching, nor can the teacher make any improvement in his teaching. Then, he may start the whole process all over again, without knowing that the efficiency is low.

The most important form of evaluation is exam which often comes too late. Students have to pass many exams, ranging from final exam to such national exams as CET 4/6(College English Text level 4/6). If college student fail in CET 4, they may not get the diploma and then most companies may deny them as employees. That's why most teachers and students are just exam-oriented. They attach great importance to passing the exam, instead of comprehensive English competency or communicative competency.

Other forms of evaluation include mid-term exam and final exam. Whatever the exam is, it i s a long time before students are checked whether they have mastered the necessary knowledge and skills they have learned. There is a lack of timely evaluation. And therefore, student may neglect daily review and practice, and may easily forget what they have learned.

\section{BOPPPS MODEL VS TRADITIONAL MODEL}

\section{A. BOPPPS Model}

In a BOPPPS model, a class is divided into six sessions-Bridge-in, Objective/Outcome, Pre-assessment, Participatory Learning, Post-assessment and Summary, each session lasting about 15 minutes - which resembles microlecture. It is based on the theory that a person's attention span lasts only 15 minutes.

1) Bridge-in: Bridge-in aims at attracting students with some pre-knowledge of the lesson and helping students focus on the content to be learned. Students may arrive at the classroom without knowing anything about what they are going to learn. They are disoriented and distracted. Therefore, it is important to gain their attention and demonstrate the value of the lesson. Strategies to by employed by teachers are: informing students with the reason and the significance to learn the lesson, or its connection with other lessons, relating a story or personal experience relative to the lesson, asking questions to introduce the lesson, providing an interesting or unusual facts, and connecting the following lesson with those they have learned.

2) Objectives or outcome: The second step is informing the students the objectives or outcome they need to obtain after learning. Objectives of a ESL class may help not only the students focus on the purpose of lesson, but also remind teachers how well they proceed toward the objectives. Furthermore, the objectives build the foundation for assessment. To decide the objectives of an ESL class, the teacher should be clear who are going to learn (the level 
of the students), what they will learn, under what condition they need to learn, and how and how well the learners will do.

3) Pre-assessment: Then comes pre-assessment of learners, where teachers will find out what learners know about the lesson. This, for one thing, will help teachers get acquainted with learner's interest and capability and tailor the lesson according to the learner's needs, for another, it allows learners to draw on their own experiences to improve participation and engagement. Strategies of pre-assessment in an ESL class include: testing necessary vocabulary and grammar concerning the lesson, asking closed or open questions, having students share their stories concerning the topic or have them brainstorm on the topic, etc.

4) Participatory Learning: Participatory learning encourages learners to participate and actively involved in the learning process. They are no longer vessels to be filled. Instead, they learn through discovery. Whereas, the teachers no longer dominate the whole class by give monotonous lecture. Instead, they organize tasks and lead students to study by themselves or from peers. Participatory learning can be achieved by interaction between teachers and the learners, and interaction between the learners themselves. Strategies of participatory learning are: pausing when it is necessary for students to reflect, discuss and analyze before they find solutions, having students form groups and discuss the issue of the lesson and them report their findings, having students analyze and fulfill certain tasks/solve a problem, study a case and simulate a situation, and do role-play.

This is student-centered class which facilitates the social construction of knowledge. In this process, students concentrate their attention on learning and actively participate in the class.

5) Post-test: In order to find out how well learners proceed in learning, an immediate test should be followed after teaching occurs. Teachers will find out whether the objectives are achieved through teaching. Post-test serves to answer such questions like: What did the learners learn? Are the desired objectives accomplished?

There are four types of post-assessment in ESL class:

- To assess if students have learned vocabulary, grammar, facts through short test with multiple choice questions or closed and open questions;

- To assess how well learners apply the knowledge they have learned through reporting their analysis on the issue and their solution to the problem or writing a short essay;

- To assess if they can communicate with others through debating or playing a role in a situation;

- To assess if they have improved their cognitive ability by asking them to solve problems or study a case.
6) Summery/closure: Summery serves to summarize what the learners have learned which facilitate students to integrate the knowledge and pave the way for a new class. Strategies to be employed include: to review the content of the class, to ask the students to give feedback on the participation and progress of the lecture, to acknowledgment of effort and achievement, to inspire them to think what they can do with the obtained knowledge, etc.

\section{B. Comparison of BOPPPS Model and Traditional Model}

1) Difference in teaching process: In BOPPPS model, a class is divided into six sessions-bridge in, objective/outcome, pre-assessment, participatory learning, post assessment, and summery, each one lasting approximately 15 minutes. "Fig. 2" The time allocation is based on the theory that a learner's attention span is around 15 minutes. After 15 minute's learning, his attention starts to drift. A change of the content of class may gain his interest and curiosity and helps student focus on new knowledge they need to learn. It resembles micro-lecture, and it seems the class is made up of 6 micro-lectures.

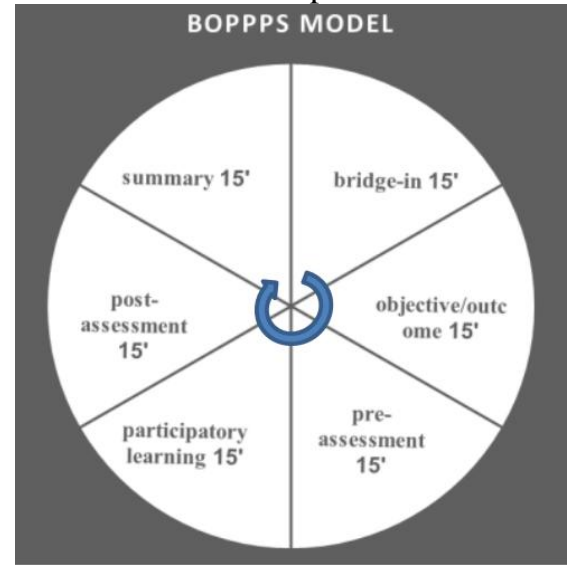

Fig. 2. The Flow of BOPPPS model.

While in a traditional ESL class, the first fifteen minutes is dedicated to review and introduce of the new class, the last ten minutes to look back what learners have learned, and the rest 60 minutes to teacher's lecturing. "Fig. 2" 60 minutes seems too long to gain students' attention. When what needs to learn is difficult or when the lecturing is monotonous, students get distracted easily. Though it may involve such participatory process as group discussion, role play, etc, it is difficult for the students play an active role in it since teacher dominates the class. 


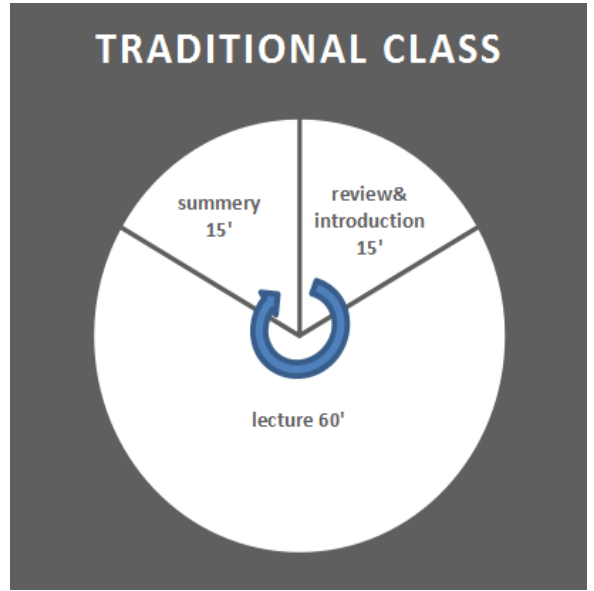

Fig. 3. The Flow of Traditional Class

With clear-cut division of the class by BOPPPS model, the class proceeds naturally. It integrates teaching objective, teaching activity, learning activity, and assessment of teaching. Firstly, with necessary bridge-in techniques, students, whose knowledge about the lesson has been activated, find it easy to integrate into the new knowledge to be learned. After the objectives are announced, they are clear in mind what they need to achieve, and what they need to do. Then, the pre-assessment may help the teacher get better informed about the condition of the students, and make necessary modification of the class. Participatory learning always ignites the class, since the teacher takes the lead, and the students are the center of the class. Their needs of learning are respected and their learning process is crystallized. The frequent interaction between the teacher and students, and the interaction between students and students facilitates active study by the students and promotes the affective interaction between the teacher and student, as well as between students and students. All their learning performance will be evaluated in post-assessment. Postassessment comes immediately after learning happens, it is not only an effective way of assessing teaching and learning, but also promote self-examination - the students will reflect on how well they have participated in study, and the teacher, based on the results, may find the drawbacks of the class and make certain adjustment in the next class.

However, there is no clear-cut division of the class in traditional ESL class. The class is roughly divided into three sessions. In the warm-up session, which resembles bridge-in, students are pushed to think about what they are going to learn and their knowledge about the new class is activated. Then without a clear objective- because it is assumed that as long as they finish study, they will know what they have learned - they start a teacher-centered class. This session may involve some questions by the teacher, and some activities, such as role-play, group discussion, etc., but the interaction is not highlighted here because the teachers have too many to lecture and students have to play a minor role. After the lecturing is over, the teacher may summarize what they have learned as soon as possible, and the evaluation may come later with some exercise of the class or even later with the final exam.
2) Student-centered VS teacher-centered: Statistics show that in traditional class teacher's lecturing accounts for $80 \%$ of the class, students' active learning makes up to $20 \%$ of the class. $70 \%$ of students are distracted in class, and only $30 \%$ may participate in the class. "Table I"

While in participatory learning, teacher acts as a facilitator and students are the center of the class. They are involved in learning mentally - they need to analyze the problem before putting forward any solutions, emotionallythey need to communicate with the teacher and other members of the group, and manually - they need to work out the problem and operate. While participation can be both active and passive, active participation is encouraged in BOPPPS model.

TABLE I. STUDENT-CENTERED VS TEACHER-CENTERED

\begin{tabular}{|c|c|c|}
\hline & $\begin{array}{c}\text { teacher-centered } \\
\text { class }\end{array}$ & teacher-centered class \\
\hline task & to impart knowledge & to enhance their ability \\
\hline type of knowledge & received wisdom & constructed \&dynamic \\
\hline teaching method & $\begin{array}{l}\text { lecturing as authority, } \\
\text { one-way }\end{array}$ & $\begin{array}{l}\text { active interaction, } \\
\text { cooperation }\end{array}$ \\
\hline role of the teacher & teacher as expert & teacher as facilitator \\
\hline $\begin{array}{ll}\text { content } & \text { of } \\
\text { teaching } & \\
\end{array}$ & $\begin{array}{l}\text { determined by the } \\
\text { teacher }\end{array}$ & $\begin{array}{l}\text { anything at anytime, } \\
\text { anywhere }\end{array}$ \\
\hline result of teaching & certification & competency \\
\hline
\end{tabular}
centered planning model: In a content-centered class, the teacher takes into account what content needs to be taught, how much time is left, how he can finish demonstrating the content in limit time, and which textbook is suitable for the class.

While in a student-centered class, what matters is how well the students perform, how much new knowledge, skills or attitude they have gained, what they can do with the knowledge they have just learned, what content they have to learn in order to accomplish the objectives of the class, and how they learn the content.

4) Reflection on teaching and learning: Under BOPPPS model, post assessment will indicate how well the students have learned and if there is any defects in teaching. It is an immediate reflection. In this process, both the teacher and the students may reflect on their action in the class. It helps them readjust their performance to achieve better result.

Whereas, in traditional class, the role of reflection is often overlooked or even diminished for it attaches to much importance to imparting knowledge.

5) Difference in evaluation: BOPPP model integrates pre-assessment and post assessment. Before learning starts, the teacher may identify how much the students know about the new content, and accordingly adjust their teaching. After learning is finished, the post assessment is immediate. For one thing, it tests how well the students have learned. For another, through the comparison with pre-assessment, it indicates the effectiveness of the teaching and learning. 
While in traditional class, there is not specific session dedicated to pre-assessment. If there is one, it is often mingled with warm-up. And its role in teaching is overlooked. Therefore, there is not assessment aiming at checking what students have truly gained through learning. Besides, there is no immediate assessment of the learning in traditional class. Therefore, it doesn't contribute to active learning from student's perspective nor improvement or adjustment in teaching from the teacher's perspective.

\section{APPLICATION OF BOPPP MODEL IN ENGLISH CLASS- CASE STUDY}

We take the intensive reading of college-level - an ESL class - as an example. The teaching targets are students who have adequate competency in reading, listening, speaking and writing in English. The topics of the textbook cover language, culture, business, science and technology. Each text consists of long and difficult sentences with new vocabulary and difficult syntax. The difficulty also lies in different way of thinking in approaching to an issue between English and Chinese embodied in the text.

In traditional class, the teacher may introduce the text briefly and then elaborates on explaining the long and difficult text, occasionally ask students to read a paragraph or answer a question. At the end of the class, the teacher summarizes what has been taught. It is sure that abundant knowledge was taught by the teacher, but is not sure how much has been digested by the student. Day by day, the students are used to receiving knowledge, instead of active thinking and critical thinking. The application of the knowledge gives way to lecturing and students seldom have a chance to practice what they have learned. It is difficult for the students to improve their linguistic competence, let alone the communicative competency. It doesn't contribute to effective improvement of cognitive ability either.

Based on BOPPPS model, I make some adjustment in the planning of intensive reading. My students are sophomores and the text is entitled as "the drawbacks of cultural globalization". My teaching planning is as following.

\section{A. Bridge-in}

To activate student's knowledge related to the text, I ask them to brainstorm on the title and then explain what cultural globalization is and the drawbacks of cultural globalization

Students may feel at loss because most of them have never pondered on, or even heard of culture globalization. To get them acquainted with the topic and arose their interest in leaning the text, I demonstrated some pictures of different ways of life between the West and China, and ask them to compare the differences in cultures between the West and China.

After this activity, students become interested in the topic. Then I encourage them to think about the elements/examples of Western culture in their daily life and its influence in Chinese culture. Then students become productive in their answers.
This is a step-by-step bridge-in, since the topic is new to students. In conclusion of this session, I make an analogy between the spread of language - which they have learned in the previous class - and the spread of the culture. With adequate information, students are inspired and get wellprepared for the next step of learning.

\section{B. Objective / Outcome}

After successfully arousing their interest, I duly state the objectives of learning.

There is general objective for the course, namely, to increase their English competence, including to enlarge their vocabulary, to improve their ability of comprehension of text and pave the way for writing and translation, and communicative competence-with the competence of language they have gained, they are encouraged to communicate with others.

I need to remind them the general objective sometimes but not so often. But I need to remind the specific objectives of the class in this session in order to get them better focus on the goal of study, so that whenever they, or I, are distracted, we need get back to track immediately.

The specific objectives of this class are

1) Basic English competence: After learning the lession, students will be able to (1) understand the meaning of each sentence/paragraphs; (2) translate and paraphrase long and difficult sentence; (3) determine the author's purpose, intended audience, tone and the text's context; (4) evaluate the evidence presented by the author and state their opinion; (5) learn the difference between Western culture and Chinese culture.

2) Application of language: Firstly, students should be able to apply the language skills they learn from the text. To be more specific, in the beginning of the text, the writer introduces the questions directly. To illustrate this, some facts and examples are followed. Then the writer focuses on the causes and the effects of cultural globalization. At last, it is concluded that the diversity of culture should be preserved. Students should get familiar with the development of the text and produce writing by drawing on the vocabulary, phrases, grammar, or structure of the text. Secondly, they will be able to solve new problems by drawing on the knowledge they have learned and way of thinking they have developed. In approach to cultural globalization, they need to think about the examples of cultural globalization. It is also necessary for them to make an analogy with the spread of English or economic globalization. Then to find out the causes of cultural globalization, they need to take historical background into consideration: the spread of culture started from colonialism or to deal with it from a new angle: the spread of multinationals poses challenges to local cultures of nonWestern societies. To analyze the effects, they need to approach to it from a global perspective: the culture of a lot 
of under-developed countries are undermined by Western culture

3) Communicative competence: Students will be able to improvise on the issue of culture and cultural globalization, as well as its causes and effects. Furthermore, with the difference between Western culture and Chinese culture in mind, they may avoid misunderstandings in the cross-culture communication with foreign friends or future foreign clients.

Above are the key points that a students need to grasp in the class. They need to test themselves if they have accomplished the objectives at the end of learning.

\section{Pre-assessment}

Firstly, I need to test how well they are familiar with the topic by asking questions tailored according to the content of the text. I start by specific questions like: Why do you celebrate Christmas? Do you like food from KFC or McDonald's? Then I gradually focus on the theme by asking questions like: Do you think Chinese culture is undermined by Western culture? These questions not only help them focus on the theme of learning but also test their ability to express a complete set of idea.

Then they need to complete a quiz on the new words, terms and grammar they are going to encounter in the learning. The quiz can be a formal one - a paper test, or an informal one-asking the students to read the words and terms I write on the blackboard, or have them explain the meaning of a long sentence that consists of various infinitives, participles, clauses, etc. This helps them get informed about the language skills they may need in learning

\section{Participatory Learning}

With adequate preparation, they begin their journey of active learning. To solve the long and difficult sentences, they are encouraged to form groups and the members discuss the text together. Then one group reports their explanation of the text, while other groups act as judge and provide.

Then I make positive comments on the report and point out the mistakes they made, if there is any. I need to highlight the key points they need to learn, especially the structure of the writing and guide them to study.

At last, we start a seminar where everyone has to share their insight they have gained or developed through learning. We further explore the causes of cultural globalization and its effects. Above all, we start to elaborate on ways to protect Chinese culture and their solutions are quite original and workable.

In the whole, I act as a facilitator, and the students play a key role.

\section{E. Post-assessment}

Tests are necessary to decide $\mathrm{f}$ they have accomplished the objective. Sometimes, I design tests according to the content of the class. Otherwise, I use the exercise following the text. Both these tests include drills on language points, namely usage of words, grammar, as well as translation and paraphrase. They serve well in testing their improvement of linguistic competence.

What's more, I ask them to write a cause-effect essay based on what they have learned. Rather than I give them a topic for writing, they need to identify an issue themselves, and elaborate on facts or examples of the issue. Then, they have to analyze the causes and effects of it before they reach any conclusion.

To test their communicative competence, they are encouraged to design a certain situation and act out a scene relating to what they have learned, or they need to start a debate or speech to demonstrate how well they have learned.

\section{F. Summary}

Students are encouraged to review objectives and reflect on what they have learned. What is more important, they need to share their views the connection of the knowledge or skills they have newly learn with those they have learned previously. In this lesson, they are required to summarize the advantage and disadvantage of cultural globalization and compare it with the globalization of English and economic globalization.

It is important to find out if there is any muddiest or clearest point in learning. If they are still unclear about something, I may explain to them.

\section{At last, I list the task of the next day's lesson.}

I find BOPPPS model contributes to effective teaching. Firstly, all the teaching tasks are finished and teaching is no longer a laborious job, nor does learning for I do not need to stand on the platform lecturing the whole class and the students do not strain themselves in passively receiving knowledge. They play an active part in class. There is more chance for them to think, discuss and practice what they have learned. Furthermore, we are clear with our objectives all the way, and we find all the objectives are accomplished at the end of the class. Above all, they find they are more confident in English study and in solving new problems.

\section{Suggestions ON USING BOPPPS MODEL}

- BOPPPS model provides a framework for the process of the class. It is not a master key to teaching. Teachers need to fill contents to each step according to specific needs of the students and requirement of the course. What's more, each session of BOPPPS model can be carried out in various ways; it is up to the teacher to decide which way to adopt based on the characteristics of the course and the content of the lesson. Furthermore, each session is not separated from one another. Instead, they should be integrated by a tactful design of the content by the teacher.

- In ESL class, it is inevitable that the students need to learn adequate vocabulary, terms, and grammar. If the teacher spends more of time dealing with them in class, it will not generate effective teaching and learning. It is advisable that BOPPPS model is used 
in combination with flipped classroom, which means that the students finish such easy task as remembering vocabulary, terms, and grammar, etc, through flipped classroom. Then with sufficient preparation, they come to the classroom and focus on more difficult tasks, such as discussing the implied meaning of the text, exchanging insight gained through learning, or solving a real problem, etc..

- The fact that the teacher-centered class gives way to student-centered one does not mean that teaches are no longer important. As facilitators, they should know the needs of their students. They need to tailor the difficulty of learning based on the interest and English level of their students. They also need to facilitate a learning environment that encourages selfstudy, active learning, critical thinking, innovation and interaction both between the teacher and student and between student and student.

\section{CONCLUSION}

The division of BOPPPS model is, in essence, a refinement of traditional class. By a clear-cut division into six sessions-bridge-in, objective/outcome, pre-assessment, participatory learning, post-assessment, and summarystudents get involved in learning step by step and the teaching is optimized. BOPPPS model also encourages active participation of students. Thus, it liberates ESL teachers from the painful efforts of teaching the content of the text. By actively involved in learning, the students improve their linguistic competency, communicative competency and cognitive ability efficiently. In all, by adopting BOPPPS model, effective teaching in ESL class is achieved.

\section{REFERENCES}

[1] Josef M. Broder, and Jeffrey H. Dorfman, "Determinants of teaching quality: What's important to students?" [J]. Research in Higher Education, 1994 (2)

[2] Hao Wenwu, "Effective teaching that Integrates Three Dimensions of Teaching Objectives" [J]. Research in Education, 2009 (01).

[3] J M Broder and J H Dorfman. "Determinants of teaching quality: what' s important to students." Research in Higher Education, 1994.

[4] Chomsky, N., Aspects of the Theory of Syntax [M], Cambridge: MA.MIT Press, 1965.

[5] Taylor,D, "The Meaning and Use of the Term Competence in Linguistics and Applied Linguistics". Applied Linguistics. 1988.

[6] Hymes,Dell, "Models of the Interaction of Language and Social Life". Directions in Sociolinguistics: The Ethnography of Communication. 1972

[7] Canal, M.and Swain, M, "Theoretical Bases of Communicative Approaches to Second Language Teaching and Testing.Applied Linguistics" [J]. 1980, 1 (1): 1-47.

[8] Pan Neng, On the Competency of College English Study. Xi'an: Xi'an Jiaotong University Press: 1997.

[9] Nie Baoyu, "A Study on the Construction of Output oriented EFL Competence", Journal of Chifeng University(Science \& Education), $2011(06)$. 